\title{
Tampering with the cell cycle's brakes
}

To stop the cell cycle, tumour suppressors such as the retinoblastoma protein ( $\mathrm{Rb}$ ) apply the brakes. A Nature paper by Anna Lasorella and colleagues describes how Id $2-$ a dominant-negative inhibitor of helix-loop-helix DNA-binding proteins - gets the wheels turning again.

Retinoblastoma protein is essential for mammalian development: knockouts die during embryogenesis. Lasorella et al. report that knocking out $I d 2$ rescues $R b^{-1-}$ embryos. Defective myogenesis kills $I d 2^{---} R b^{-/-}$mice shortly after birth, but they show none of the hallmarks of $R b^{-/-}$mice - too much proliferation and apoptosis in the haematopoietic and nervous systems. Id 2 therefore perpetrates the $R b^{-/-}$phenotype; but how? Immunoprecipitates revealed that active, hypophosphorylated $\mathrm{Rb}$ binds Id 2 and, to tip the balance against tumour suppression, Id2 has to be in molar excess of $\mathrm{Rb}$.

An intact $\mathrm{Rb}$ pathway is needed to prevent tumorigenesis, so Lasorella and colleagues asked whether Id 2 is overexpressed in neuroblastoma cell lines, in which N-myc amplification typically bypasses Rb. Remarkably, Id 2 expression correlated with $\mathrm{N}-m y c$ amplification. What's more, Myc's effect on Id2 expression (which also extends to c-Myc) is direct, owing to two high-affinity Myc-binding sites in the Id 2 promoter. Deletion of these sites abolished Id2 expression in response to Myc.

By producing a surfeit of Id, then, Myc can override Rb's attempts to halt the cell cycle. But what targets of Id are responsible for the $R b^{-/}$phenotype? And what about the other Id family members, Id 1 and Id 3 ? These questions, and others, await the next cycle tour.

Cath Brooksbank

\section{(4) References and links}

ORIGiNAL RESEARCH PAPER Lasorella, A. et al. Id2 is a retinoblastoma protein target and mediates signalling by Myc oncoproteins. Nature 407, 592-598 (2000)

FURTHER READING Yokota, Y. et al. Development of

peripheral lymphoid organs and natural killer cells depends on the helix-loop-helix inhibitor Id2.Nature 397, 702--706 (1999)

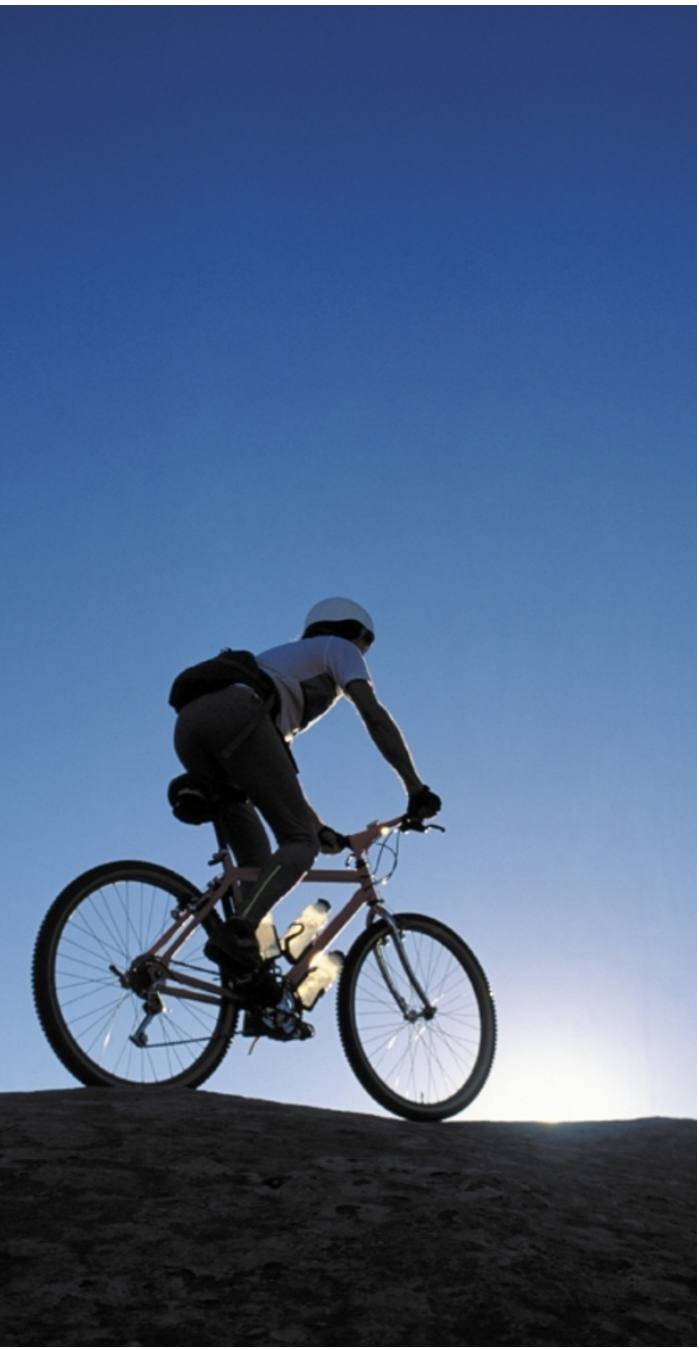

\section{APOPTOSIS}

\section{Viral pirates hijack Bcl-2}

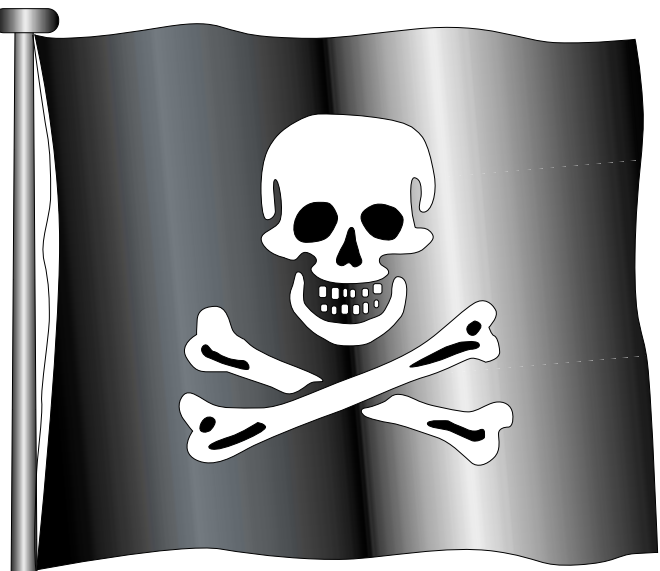

Viruses are modern-day buccaneers. They ride the cellular seas, hijacking proteins and using them to promote their own survival. But how? Ojala et al., reporting in the November issue of Nature Cell Biology, describe how the Kaposi's sarcoma herpesvirus (aka human herpesvirus 8; HHV8) interferes with apoptotic signalling pathways in its host.
The virus encodes a pirated cyclin ( $v$ cyclin), which forms a complex with a cellular cyclin-dependent kinase, CDK6. This complex can induce apoptosis, and Ojala et al. now show that it probably does so by phosphorylating - and inactivating - the cellular anti-apoptotic molecule Bcl-2. The authors find that Bcl-2 and CDK6 associate in cell extracts, and they show that the targets for phosphorylation are two serine residues in an unstructured 'loop' region of cellular Bcl-2.

But herein lies a paradox. Why should the virus inactivate a molecule that protects the host cell from apoptotic death? One might think it in the best interests of the virus to keep its host alive. It turns out, however, that cellular Bcl-2 has other functions that the virus finds less than savoury; for instance, it has been reported to impair cell-cycle progression when overexpressed. Moreover, host cell death is advantageous to the virus in that it allows the spread of viral particles.
There is a problem, though — the risk that, when the virus blocks cellular Bcl-2, the host cell will die before the viral replication cycle is complete. Here, in an ultimate act of viral skulduggery, HHV8 produces its own Bcl-2 homologue. This virus-encoded protein lacks the crucial unstructured loop, so it cannot be phosphorylated or inactivated by v-cyclin-CDK6.

Infection of host cells with HHV8 has previously been shown to be linked to apoptosis, and the lesions associated with Kaposi's sarcoma contain some apoptotic cells. The next step, then, will be to work out how the acts of viral piracy uncovered by Ojala et al. link HHV8 to tumour formation and to the development of Kaposi's sarcoma.

69) References and links ORIGINAL RESEARCH PAPER Ojala, P. M. et al. The apoptotic $\mathrm{v}$-cyclin-CDK6 complex phosphorylates and inacticates Bcl-2. Nature Cell Biol. 2, 819-825 (2000)

FURTHER READING Hardwick, J. M. Cyclin' on the viral path to destruction. Nature Cell Biol. 2, E203-E204 (2000) | Desagher, S. \& Martinou, J. C. Mitochondria as the central control point of apoptosis. Trends Cell Biol. 10, 369-377 (2000) 